\title{
Pronunciation errors by Spanish learners of Dutch: A data-driven study for ASR-based pronunciation training
}

\author{
Pepi Burgos, Catia Cucchiarini, Roeland van Hout, Helmer Strik \\ Department of Linguistics, Radboud University Nijmegen, The Netherlands \\ \{j.burgos, c.cucchiarini, r.vanhout, h.strik\}@let.ru.nl
}

\begin{abstract}
In this paper we report on a study on pronunciation errors by Spanish learners of Dutch, which was aimed at obtaining information to develop a dedicated Computer Assisted Pronunciation Training (CAPT) program for this fixed language pair (Spanish L1, Dutch L2). The results of our study indicate, that, first, vowel errors are more frequent and variable than consonant mispronunciations. Second, Spanish natives appear to have problems with vowel length, vowel height, and front rounded vowels. Third, they tend to fall back on the pronunciation of their L1 vowels.

Index Terms: L2 phonology acquisition, language learning, CAPT
\end{abstract}

\section{Introduction}

Research on second language (L2) acquisition has shown that adult learners have difficulties in mastering L2 sound patterns with the ability of a native speaker [1], [2] and that the native language (L1) influences the acquisition of L2 phonology [3], [4]. A foreign accent does not always hinder intelligibility, but can be disadvantageous for successful interaction and social acceptance [5]. Since pronunciation can never be sufficiently practiced in the classroom due to lack of time, there is a growing demand for CAPT applications that make use of Automatic Speech Recognition (ASR) to provide sufficient practice and feedback on pronunciation.

A possible approach to effective CAPT consists in developing systems that address specific L1-L2 combinations, as this enables to provide tailored pronunciation exercises [6], [7]. An important step in developing such systems is quantitative, data-driven analysis of the pronunciation errors made by L2 learners with the same L1 [7].

In this paper we report on a study on the pronunciation errors made by Spanish learners of Dutch that we carried out with a view to developing a CAPT system for this target group. Previous studies mainly addressed how Spanish L1 can affect perception of Dutch L2 [8], [9], [10], [11] while less attention was paid to speech production. This is the aim of the present paper which is divided as follows. In section 2 we present the research background, including a brief description of the phonological differences between Spanish and Dutch. In section 3 we describe the design of our study, followed by the results in section 4 . The results are then discussed in section 5 where conclusions are drawn and some suggestions concerning the development of pronunciation training materials are advanced.

\section{Research background}

\subsection{The Phonology of Spanish and Dutch}

Vowels: Dutch and Spanish have different vowel systems, as we can observe in Figure 1.

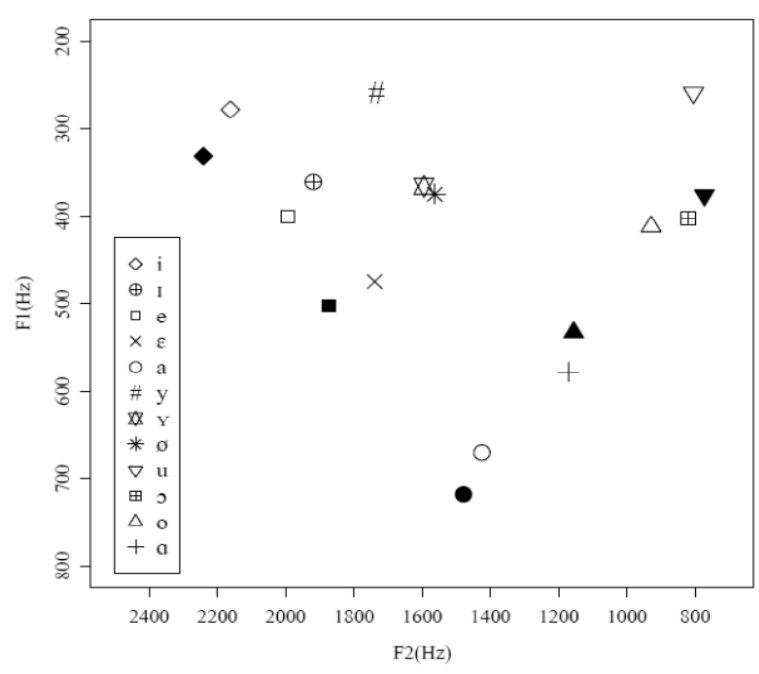

Figure 1 Spanish (black symbols) and Dutch vowel spaces (without the diphthongs), according to their F1 and F2 values.

The first, and most obvious, difference is that Spanish has five vowels (/a, e, i, o, u/) [12], whereas Dutch has fifteen unreduced vowels (tense vowels: /i, y, u , e, ø, o, a/; lax vowels: /I, $\varepsilon$, ग, Y, a/; three diphthongs: / $\varepsilon \mathrm{i}$, oey, ou/) and the reduced vowel schwa /a/ [13]. The second is that Dutch has a tense/lax distinction, whereas such distinction does not exist in Spanish. The third difference is that in Spanish back vowels are all rounded and front vowels are all unrounded, whereas in Dutch

there are also four front rounded vowels: /Y, y, ø, oey/.

Consonants: Spanish and Dutch share many consonantal sounds except the $/ \mathrm{h} /$ and $/ v /$ which are only found in Dutch and the phonemes $/ \theta /, / \mathrm{t} s /$ and $/ \mathrm{r} /$, only found in Spanish. Another difference is that Spanish has a tendency for an open syllable structure (CV), whereas Dutch has a preference for a closed one (CVC) [12], [14]. 


\subsection{Research on Spanish natives' difficulties with Dutch}

Most research on Spanish natives' difficulties with Dutch is related to speech perception, in particular the perception of Dutch vowels [9], [10]. Difficulties with the /a-a/ and /i-I/ contrasts and with the identification of the Dutch vowels /i, y, I, $\mathrm{Y}, \mathrm{u} /$ have been reported in Peruvian and Iberian Spanish learners [11]. Difficulties in speech perception also appear to be related to interference from L1 and L2 orthography [15]. Limited research on Dutch speech production by Spanish learners (among other L1s) also indicated influence from orthography and showed that the most frequent mispronunciations concerned the vowels $/ \mathrm{a}, \mathrm{a}$, $\mathrm{Y}, \varnothing$, ci, oey/ and the consonants /h, $\mathrm{x}, \mathrm{t} /[16]$.

Based on the phonological and orthographic differences between Spanish and Dutch and on previous research on Spanish learners of Dutch, we can predict that Spanish natives, with their own five vowel system, will have problems in reconciling fifteen unreduced vowels and the reduced vowel schwa in Dutch. In particular, we expect problems in the production of the tense/lax distinction and the Dutch front rounded vowels (/Y, y, ø, oey/). Difficulties concerning the pronunciation of the Dutch consonants $/ \mathrm{h} / \mathrm{\text {and }} / \mathrm{v} /$ and clusters are also expected. Finally, both vowels and consonant mispronunciations are likely to occur owing to orthographic interference [15], [17].

\section{A data-driven study of Spanish L2 Dutch}

The sources mentioned in the previous section can provide information about the pronunciation errors that Spanish learners of Dutch are likely to make. For more objective and precise information on this point a bottom-up, data-driven approach is required to obtain quantitative data on the frequency of occurrence and the contexts of the various errors, which, in turn, is necessary to develop error detection algorithms and to design useful pronunciation exercises [7]. For this purpose, we decided to use speech recordings of Spanish students of Dutch that had been made at the Radboud University in Nijmegen.

\subsection{Participants}

The participants in this research were five adult male and eighteen adult female native speakers of Spanish from Spain and Latin American countries who were living in the Netherlands and were learning Dutch at Radboud in'to Languages, the university language centre of the Radboud University. They were placed in courses based on their proficiency level (A1, n=4; 2 , $\mathrm{n}=8 ; \mathrm{B} 1, \mathrm{n}=6 ; \mathrm{B} 2, \mathrm{n}=5$ ) according to the Common European Framework of Reference for Languages (CEFR) [18].

\subsection{Material and data analysis}

The recordings were answers given by the participants in speaking exercises of Dutch official oral exams and were orthographically transcribed in Praat [19] using SAMPA (Speech Assessment Methods Phonetic Alphabet) phonetic script [20].

It is important to underline that the choice for this type of material adds to the realistic character of our research. In general, studies on L2 speech tend to use laboratory speech because this has the advantages that it can be guided and controlled. However, this detracts from the generalisability of the results to real-life situations. Our speech material is relatively natural and realistic and reflects the occurrence of the various speech sounds in real-life speech.

An automatic phonemic transcription was generated using pronunciation variants of the lexicon of the Spoken Dutch Corpus [21]. Manually corrected transcriptions that represent how the words were actually realized by our participants were generated. The transcriber, a trained expert, judged every phoneme and annotated deletions, substitutions and insertions.

To check the accuracy of the annotations we asked a second experienced rater. Intertranscriber agreement between the two annotators was high (kappa $=.826$ for the vowels; kappa $=.983$ for the consonants), indicating that the errors identified by the first transcriber were also identified by the other transcriber to a considerable extent.

Confusion matrices comparing the automatically generated transcription (containing the target phonemes) with the manually corrected phonemic transcriptions (containing the realized phonemes) were then generated. These matrices provide information on overall performance, but also on details of target phoneme realization, as incorrect realizations of a phoneme might lead to intelligibility problems.

\section{Results}

We first calculated overall percentages of correctly pronounced segments per CEFR level. Note that since our study was not longitudinal, the results for the various CEFR levels cannot be interpreted as students' progress, but they do indicate that some pronunciation errors were specific for the A1 level and disappeared at A2 level, while other mispronunciations remained at $\mathrm{B} 1$ and $\mathrm{B} 2$ levels.

Table 1 indicates that the overall mean percentage vowel errors $(18 \%)$ is relatively high in comparison to consonant errors (3\%). One of every six vowels is erroneously realized, but the percentage may vary for the different vowels.

Table 1. Means and standard deviations (SD) of proportions correct realizations per CEFR level.

\begin{tabular}{|l|l|l|l|l|l|l|}
\hline Level & \multicolumn{2}{|l|}{ Total correct } & \multicolumn{2}{l|}{$\begin{array}{l}\text { Consonants } \\
\text { correct }\end{array}$} & \multicolumn{2}{l|}{$\begin{array}{l}\text { Vowels } \\
\text { correct }\end{array}$} \\
\hline A1 & .82 & .04 & .92 & .02 & .71 & .06 \\
\hline A2 & .92 & .04 & .98 & .01 & .86 & .08 \\
\hline B1 & .91 & .03 & .97 & .01 & .83 & .06 \\
\hline B2 & .93 & .05 & .98 & .02 & .86 & .10 \\
\hline Overall & .90 & .05 & .97 & .03 & .82 & .09 \\
\hline
\end{tabular}

An ANOVA analysis on the percentages total correct segments returned a significant result for proficiency level $(\mathrm{F}=$ $6.785, \mathrm{p}=.003$, partial eta squared $=.517$ ). The A1 informants have the lowest percentage correct and there is no overlap with the other three level groups (A2, B1, B2). Within groups, among participants with the same proficiency level, the variation in percentage correct is fairly large. Post hoc tests (Tukey HSD) for all three categories (total, consonants, vowels) revealed a distinction between A1 versus the higher levels (A2, B1, B2), and no distinction among the three higher levels. An interesting 
result, which means that the decrease in pronunciation errors seems to taper off after the A1 level.

Since the percentage of correct realizations for consonants is high (.97 overall), we decided to focus our analyses on the vowels as they appear to be more problematic for Spanish learners of Dutch. Vowel errors are not only more frequent, they also appear to be more variable among informants

Table 2 presents a full list of vowels displaying the pronunciation errors for sixteen target vowels (the fifteen unreduced vowels of Dutch plus the reduced vowel schwa). We present the relative frequency of occurrence of the errors (as reflected by percentages of erroneous pronunciations relative to the total number of occurrences of the phoneme). As we can see in Table 2 the most frequent mispronunciations of Dutch vowels $(>5 \%)$ which were noticeable at all CEFR levels concerned the phonemes /e , I , y, y , ə, œy/. Mispronunciations that are still noticeable at B2 level can be considered as examples of persistent errors.

Table 2. Frequency of vowel mispronunciations per target vowel category and CEFR level (A1, A2, B1, B2); $\mathrm{Th}=\mathrm{Target}$ phoneme, $\mathrm{N}=$ Number of occurrences, $\%$ Error $=$ Error percentage, Real=Realization, Del=Deletion

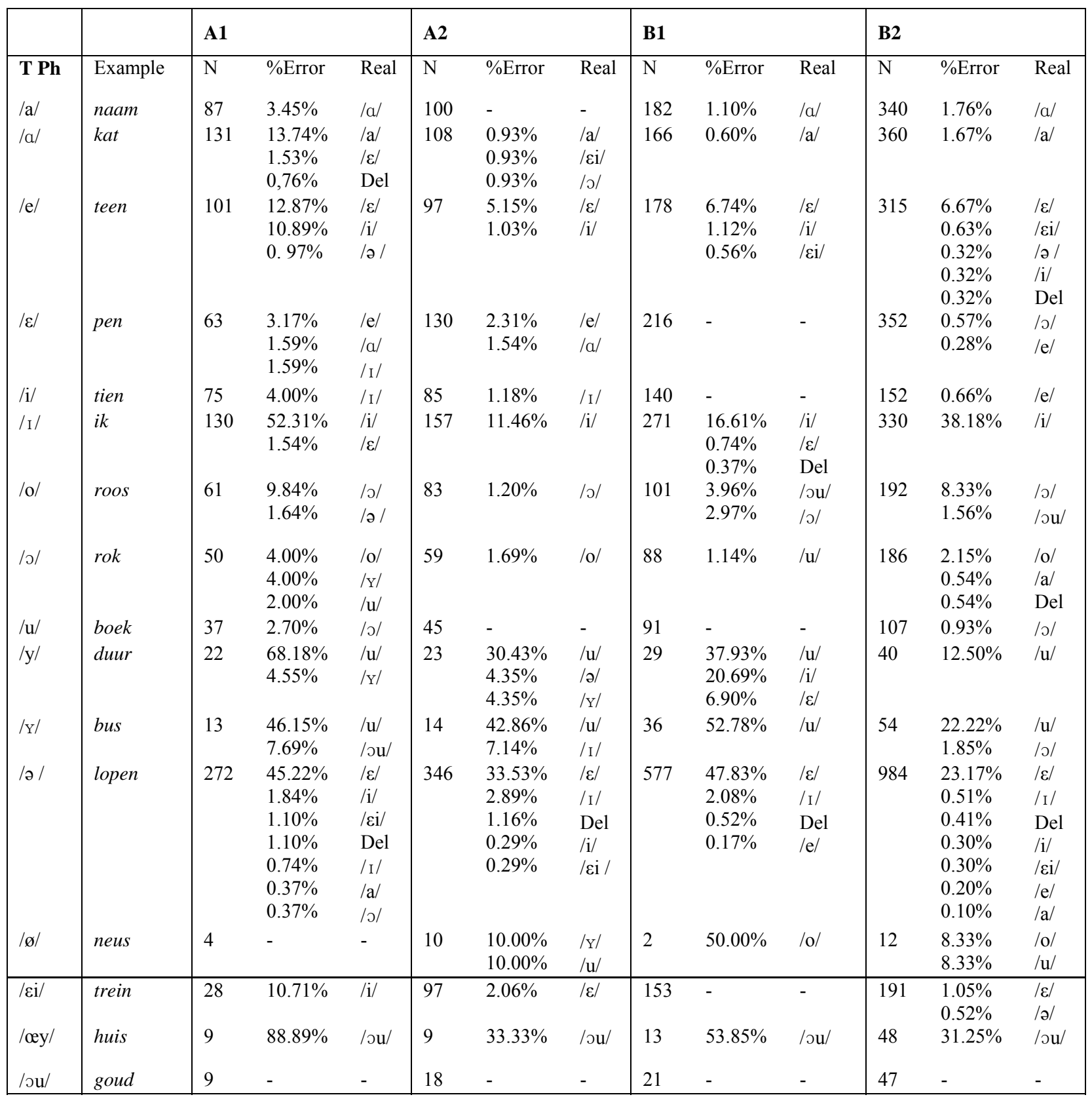




\section{Discussion and conclusions}

The results of the present study are in line with those of previous research on pronunciation errors in Dutch L2, which indicate that vowels are in general more problematic than consonants. Vowel mispronunciations are often related to vowel length (including the tense/lax distinction), but vowel height, rounding of front vowels and orthographic interference also appear to play a role. Difficulties with vowel length are evident from the mispronunciations of $/ \mathrm{a} /$ as $/ \mathrm{a} /$ and $/ \mathrm{o} / \mathrm{as} / \mathrm{J} /$, producing vowels which are closer to the Spanish /a/ and /o/. Problems regarding vowel height are noticeable in the mispronunciations of $/ \mathrm{I} /$, which is located in the center of the Dutch vowel space corresponding to an empty area in the Spanish vowel spectrum, as shown in Figure 1. Spanish learners tend to resort to the Dutch /i/ which is higher and more peripheral like the Spanish /i/. The diphthong /œy/ is often realized in back position resulting in /ou/. The schwa $/ \partial /$ is frequently substituted by $/ \varepsilon /$ or $/ \mathrm{e} /$ when it is represented by the grapheme $e$, which seems to reveal interference from orthography.

Table 3 Vowel confusions in A1, A2, B1 and B2, + = \% error $>5$, - = \% error percentage $<5$ ), Error source: $L=$ Length, $H=$ Height, $F=$ Front round, $O=$ Orthographic interference.

\begin{tabular}{|c|c|c|c|c|c|c|c|}
\hline \multicolumn{3}{|c|}{ Confusion } & \multicolumn{4}{|c|}{ Levels } & \multirow{2}{*}{$\begin{array}{l}\text { Error } \\
\text { source }\end{array}$} \\
\hline & & & A1 & A2 & B1 & B2 & \\
\hline$/ a /$ & $\rightarrow$ & /a / & + & - & - & - & $\mathrm{L}$ \\
\hline /o/ & $\rightarrow$ & /o/ & + & - & - & + & $\mathrm{L}$ \\
\hline /e/ & $\rightarrow$ & $/ \varepsilon /$ & + & + & + & + & $\mathrm{H}$ \\
\hline /I/ & $\rightarrow$ & /i/ & + & + & + & + & $\mathrm{H}$ \\
\hline /e/ & $\rightarrow$ & /i/ & + & - & - & - & $\mathrm{H}$ \\
\hline /œy/ & $\rightarrow$ & /ou/ & + & + & + & + & $\mathrm{F}$ \\
\hline /Ø/ & $\rightarrow$ & /o/ & - & - & - & + & $\mathrm{F}$ \\
\hline /عi/ & $\rightarrow$ & /i/ & + & - & - & - & $\mathrm{O}$ \\
\hline$|a|$ & $\rightarrow$ & $/ \varepsilon /$ & + & + & + & + & $\mathrm{O}$ \\
\hline$/ \mathrm{y} /$ & $\rightarrow$ & $/ \mathrm{u} /$ & + & + & + & + & $\mathrm{F} / \mathrm{O}$ \\
\hline$/ \mathrm{Y} /$ & $\rightarrow$ & $/ \mathrm{u} /$ & + & + & + & + & $\mathrm{F} / \mathrm{H} / \mathrm{O}$ \\
\hline /ø/ & $\rightarrow$ & $/ \mathrm{u} /$ & - & + & - & + & $\mathrm{F} / \mathrm{H} / \mathrm{O}$ \\
\hline
\end{tabular}

Table 3 presents a synopsis of vowel confusions per CEFR level and their possible sources. We can observe mispronunciations concerning length (L, which combines with problems in the tense/lax distinction), contrast in vowel height $(\mathrm{H})$, and front round $(\mathrm{F})$. When we look at the results of the confusions, we see that the realizations are always close or similar to the five Spanish vowels. By looking at the possible error sources, it seems that the five Spanish vowels function as attractors for the Dutch vowels. This phenomenon in the production data has strong affinities with errors in perception. Further analysis will be required to gain more insight into the similarities and differences of error patterns in the perception and production of Spanish learners of Dutch.

The way the vowels pattern is summarized in Table 4, in which a Dutch vowel is ordered under the Spanish vowel that has the highest matching scores. Table 4 indicates the impact of the L1 phonological system on L2 vowel production. The Dutch /I/ is the lax counterpart of the Dutch tense vowel /e/, but for the Spanish learners the lax counterpart is the $/ \varepsilon /$ and the $/ \mathrm{I} /$ is subsumed under the attractor/i/. This might be explained by the influence of orthography since in Spanish the grapheme $i$ corresponds to the Spanish phoneme /i/. This process is mirrored by the $/ Y /$, the lax front round vowel, which is realized as the back round vowel $/ \mathrm{u} /$. These shifts may be strengthened by orthographic similarities as in Spanish the grapheme $u$ corresponds to the Spanish vowel /u/.

Table 4 The five Spanish vowels as attractors of fifteen Dutch vowels; /ou/ not included, as no mispronunciations were found.

\begin{tabular}{|l|l|}
\hline Spanish vowel attractor & Dutch vowels attracted \\
\hline /a/ & /a/,/a / \\
\hline /e/ & $/ \mathrm{e} /, / \varepsilon /, / \mathrm{a} /$ \\
\hline$/ \mathrm{o} /$ & $/ \mathrm{o} /, / \mathrm{o} /, / \mathrm{d} /$ \\
\hline /i/ & $/ \mathrm{i} /, / \mathrm{I} /, / \varepsilon \mathrm{i} /$ \\
\hline /u/ & $/ \mathrm{u} /, / \mathrm{y} /, / \mathrm{Y} /, / \mathrm{oey} /$ \\
\hline
\end{tabular}

The results of our study allow the following conclusions. First, among Spanish learners of Dutch L2, vowel errors are more frequent and variable than consonant mispronunciations. Second, Spanish learners appear to have problems with vowel length, vowel height, and front rounded vowels. Third, they tend to fall back on the pronunciation of their L1 vowels. And fourth, orthographic interference also causes mispronunciations.

On the basis of our results some suggestions concerning the development of pronunciation training materials for this language pair (Spanish L1, Dutch L2) can already be advanced. First, several errors appear to be caused by orthographic interference and can then be repaired by focusing on the grapheme-phoneme relationships for the Dutch sounds in question. Second, difficulties with contrasts in length, height and front rounding can be remediated by minimal pair exercises which point out such contrasts. Audiovisual feedback such as graphical displays of the vocal tract and articulators can be employed to direct the learner's attention to specific auditory and/or articulatory properties of Dutch vowels.

To summarize, the aim of the present study was to gain insight into the pronunciation errors made by Spanish learners of Dutch L2. Our research has produced a detailed overview of vowel errors from which we have tried to identify the most frequent errors and their possible sources. The resulting inventory can be used as a guideline in developing Computer Assisted Pronunciation Training (CAPT) systems that make use of Automatic Speech Recognition (ASR) to provide instantaneous and personalized feedback on Dutch L2 pronunciation. In future research we will investigate whether such fine-tuning of current CAPT helps students achieve a better pronunciation in Dutch as a second language.

\section{Acknowledgements}

We would like to thank Joost van Doremalen for his help in processing the speech files and calculating the required measures, and Radboud in'to Languages for making the recordings of the language learners available to us. 


\section{References}

[1] Long, M., "Maturational constraints on language development", Studies in Second Language Acquisition, 12:251-285, 1990.

[2] Birdsong, D. and Molis, M., "On the evidence for maturational constraints in second language acquisition", Journal of Memory and Language 44(2):235-249, 2011.

[3] Flege, J.E. , "Second language speech learning: Theory, findings and problems", in W. Strange [Ed], Speech perception and linguistic experience: Issues in cross-language research, 233-227, York Press, 1995.

[4] Best, C.T., "A direct realist view of speech cross language speech perception", in W. Strange [Ed], Speech perception and linguistic experience: Issues in cross- language research, 71-206, York Press, 1995.

[5] Brennan, E. and Brennan, J., "Accent scaling and language attitudes: reactions to Mexican American English speech", Language and Speech, 24(3):207-221, 1981.

[6] Witt, S.M., "Automatic error detection in pronunciation training: Where we are and where we need to go", IS ADEPT Proc., 1-8, 2012.

[7] Strik, H., "ASR-based systems for language learning and therapy", IS ADEPT Proc., 9-14, 2012.

[8] Escudero, P. and Boersma, P., "Bridging the gap between L2 speech perception research and phonological theory", Studies in Second Language Acquisition, 26(4):551-585, 2004.

[9] Escudero, P., Benders, T. and Lipski, S., "Native, non-native and L2 perceptual cue weighting for Dutch vowels: The case of Dutch, German, and Spanish listeners", Journal of Phonetics 37:452-465, 2009.

[10] Escudero, P., and Williams, D., "Perceptual Assimilation of Dutch vowels by Peruvian Spanish listeners", Journal of the Acoustical Society of America, 129(1):1-7, 2011.

[11] Escudero, P., and Williams, D., "Native dialect influences secondlanguage vowel perception: Peruvian versus Iberian Spanish learners of Dutch. Journal of the Acoustical Society of America Express Letters, 131(5):406-412, 2012.

[12] Hualde, J.I.," The sounds of Spanish", Cambridge University Press, 2005.

[13] Booij, G., "The phonology of Dutch", Clarendon Press, 1995.

[14] Tropf, H. , "Sonority as a variability factor in second language phonology", in A. James and J. Leather [Eds], Sound patterns in second language acquisition, 173-191, Foris Publications, 1987.

[15] Escudero, P. and Wanrooij, K., "The effect of L1 orthography on non-native vowel perception", Language and Speech, 53(3):343$365,2010$.

[16] Neri, A., Cucchiarini, C., and Strik, H., "Selecting segmental errors in L2 Dutch for optimal pronunciation training", IRAL International Review of Applied Linguistics in Language Teaching, 44:357-404, 2006.

[17] Young-Scholten, M. , "Orthographic input in L2 phonological development", in P. Burmeister, P. Piske, and A. Rohde [Eds.], An integrated view of language development - Papers in honour of Henning Wode, 263-279, Wissenschaftlicher Verlag Trier, 2002.

[18] CEFR (Common European Language of Reference for Languages), http://www.coe.int/t/dg4/linguistic/cadre1_en.asp.

[19] Boersma, P. and Weenink, D., "Praat: Doing phonetics by computer", http://www.praat.org., 2010.

[20] Wells, J., "SAMPA. Computer Readable Phonetic Alphabet", http://www.phon.ucl.ac.uk/home/sampa, 2004.

[21] Oostdijk, H.J., "The design of the Spoken Dutch Corpus", in P. Peters, P. Collins, A. Smith, [Eds], New Frontiers of Corpus Research, Rodopi, 105-112, 2002. 